International Journal of Instruction e-ISSN: 1308-1470 • www.e-iji.net

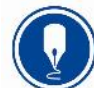

October $2021 \bullet$ Vol.14, No.4

p-ISSN: 1694-609X

pp. 173-186

Article submission code:

20200828083603

Received: 28/08/2020

Revision: 01/03/2021
Accepted: 25/03/2021

OnlineFirst: 17/07/2021

\title{
Visualization of Learning and Memorization: Is the Mind Mapping Based on Mobile Platforms Learning More Effective?
}

\section{Irina Leontyeva}

Kazan Federal University, Yelabuga, Russian Federation, leontyevairi@ rambler.ru

\section{Nikolay Pronkin}

Sechenov First Moscow State Medical University (Sechenov University), Moscow, Russian Federation, pr_nick@mail.ru

\section{Milena Tsvetkova}

Sofia University, Sofia, Bulgaria, milenaic@uni-sofia.bg

$$
\mid
$$

The purpose of the study is to compare the effectiveness of mind mapping in the traditional and mobile learning environments. The study explores whether traditional offline learning activities, including mind mapping, can be improved when using online learning platforms. Mind mapping was used in the entrepreneurship course on launching startups to brainstorm and present a business idea. The study was conducted in 2020 and involved 271 undergraduate medical students studying at Sofia University, Bulgaria and Sechenov First Moscow State Medicinal University, Russia. The results of the experiment showed that students who studied in the traditional offline environment performed better compared to those who used their mobile devices. The general concept of mobile learning has been considered. Thus, the approach enables students to choose the most suitable devices for solving various problems. In order to increase the effectiveness of mind mapping in the educational process, tasks can be performed offline and online. The practical significance of the results obtained lies in the fact that they allow the selection of the most effective offline and mobile learning technologies to make mind maps.

Keywords: concept mapping, mind mapping, mobile learning, online learning, smartphone, e-learning

\section{INTRODUCTION}

Mind mapping (MM) is one of the methods of visualization and structuring of heterogeneous information presented as a tree graph. Mind mapping is based on the principle of arranging heterogeneous pieces that have a common idea and are centered around one concept; as a rule, a sheet of paper is used for this purpose. For example, this may be an event plan, a lecture note, the contents of a book, a product or project concept, a brainstorming scheme, etc. (Fauzi and Degeng, 2018). The diagram can be

Citation: Leontyeva, I., Pronkin, N., \& Tsvetkova, M. (2021). Visualization of Learning and Memorization: Is the Mind Mapping Based on Mobile Platforms Learning More Effective? International Journal of Instruction, 14(4), 173-186. https://doi.org/10.29333/iji.2021.14411a 
black and white; however, the use of design elements, such as various colors, patterns, symbols, and keywords, is recommended. Mind mapping was introduced by the British psychologist Tony Buzan (1942-2019), who developed the method in the early 1970s (Buzan and Griffiths, 2013).

Research devoted to the application of MM in various domains shows a number of features that determine its successful implementation. The major factor is the convenience of visualization and structuring of information that is supported by simplicity and easy learning (Kamli, 2019). There is evidence that MM contributes to better memorization of information. From this perspective, MM is usually contrasted with linear presentation of information (Hidajat et al., 2020). However, a convenient and simplified structure of a tree graph ensures quick memorization of the key aspects (Rezapour-Nasrabad, 2019). This is also facilitated by convenient and compact arrangement of a significant amount of information. Analytically, MM allows establishing unobvious relationships between pieces due to the complete presentation of relevant information. This contributes to deeper insights into the topic under study and easy access to the information noted. Psychological and medical studies describe simultaneous activation of analytical and creative thinking when using MM, which is associated with the work of both brain hemispheres (Muhlisin, 2019).

The development of mobile learning technologies transforms MM and makes it focus on the use of online tools (Araujo and Gadanidis, 2020). At the same time, training methodology should be properly and carefully organized to preserve the creative and analytical potential of MM.

The scientific novelty of the study is a comparative analysis of MM effectiveness in the traditional and mobile learning environments, as well as new experimental data confirming the difference in the use of MM in traditional and mobile learning.

\section{Literature Review}

MM is one of semi-formal approaches to the visualization and generalization of information that are collectively called information mapping. Concept mapping (CM) and argumentation mapping (AM) are other similar and complementary approaches (Davies, 2011). CM, unlike MM, is more structured and formal; it does not provide for the use of design elements. CM is represented as a tree structure, the root of which, unlike MM, is not in the middle of the diagram, but in its upper part (Bendixen and Klimow, 2019). AM is the most formalized approach; a diagram represents the relationship between the thesis and multiple arguments that can both confirm and deny the thesis (Nesbit et al., 2019). The three diagrams are widely used in pedagogy (Rapanta and Walton, 2016). The assessment of the use of MM in education confirms its convenience and ease of use (Chang et al., 2018). Researchers note the possibility of adding interactive elements to diagrams as an important aspect of the use of MM in education (Elmunsyah et al., 2019).

The development of interdisciplinary creativity is determined by the positive impact of MM on improving the skills of creating technical and other specialized texts (Marashi and Kangani, 2018). A number of studies confirm sustainable development of 
entrepreneurial qualities when using MM tools (Gargouri and Naatus, 2017). The conclusions are based on the evaluation of the effectiveness of MM for the development of critical thinking and decision-making skills (Nurdin and Damayanti, 2020). MM allows students to explore and illustrate various associative concepts, establish stable and visual relationships between ontological entities, and, thus, better assimilate the subject. The combination of MM and AM enables students to substantiate theses and link statements to facts (Kurilova et al., 2019).

MM disadvantages are determined by its features, such as simplification and generalization of details. Therefore, MM is rarely used to describe complex subject areas that require in-depth analysis and identification of hidden relationships (Odah and Hendy, 2019).

Mind maps are paper drawings, or graphic or hypertext documents processed by specific computer software. MM is widely used in pedagogy, psychology, management, entrepreneurship, knowledge management, creative problem solving, and medicine (Khalifa, 2017).

The high efficiency of mind mapping as a semantic supporting effect for the associative preservation of a large volume of complex information has been proven (Spanoudis \& Demetriou, 2020). Since today there is no single, confirmed and generally accepted model of human memory, there cannot be an exhaustive description of the connection between mind mapping and its mechanisms (Camina \& Güell, 2017). However, there are practically no studies of neurophysiological mechanisms of the effectiveness of this method, and only some works consider it as an example when studying some specific features of the functioning of spatial and long-term memory (Herweg \& Kahana, 2018). The formation of complex visually oriented symbolic forms of information fixation is associated with spatial perception, the work of the so-called spatial neural groups and basic survival functions, such as memorizing the road, the formation of reference visual objects in space, finding the path, etc. (Camina \& Güell, 2017; Beaty, Sel, \& Schacter, 2019). The use of visual memory maps refers to very deep neurophysiological mechanisms, the action of which is unconditionally and reliably supported in the functioning of the higher nervous system.

Nowadays, there are dozens of applications and services that provide users with opportunities to use MM and create diagrams (Kirschner et al., 2012). The software is available as a desktop application, a browser-based application, as well as a mobile application for both Android and iOS. The application has free or paid versions. MM is also supported by the applications designed for complex solutions, for example, Microsoft Visio or Compendium.

The basic requirements for the software that supports MM and is used in the educational process are (Lin et al., 2020) a free license, possibility of collaborative learning, graphics conversion, hyperlink support, the use of design elements (colors, images, tags, etc.).

The development of software that enables schematic presentation of information triggered the argument about the effectiveness of the two approaches, namely, 
traditional paper-based mind mapping and the electronic option. Supporters of hardcopy diagrams rely on the evidence that there is a more creative process achieved manually (Parikh, 2016). At the same time, electronic diagrams can ensure collaboration (Zipp and Deluca, 2020). Thus, the benefits of paper or electronic media depend on a number of details determined by the context of use (Syakur et al., 2020).

Another technology to use MM is recently developed mobile applications that allow users to create mind maps directly from their smartphones. The approach correlates with the concept of mobile learning (Han and Ellis, 2019) and makes it possible to implement the related principles of collaborative learning (Cress et al., 2019), individual learning (Starov et al., 2014), active learning (Bosman and Fernhaber, 2019), and gamification (Lavoué et al., 2019), as well as to integrate MM tools into the learning management system (LMS) (Boyarchuk et al., 2018). However, the effectiveness of MM in mobile learning is closely associated with the limitations and lack of functionality of mobile devices (Harris, 2017). Today there is a lack of studies describing conditions for the improvement of learning experiences based on the use of MM, including in the mobile learning environment. The present study aims to partially eliminate this gap.

All studies found by the authors on the use of memory cards are devoted to various features of their use and aspects of interaction with these tools in different types of education. At the same time, both drawn and electronically created mind maps were most often used in parallel and without distinction. No research has been carried out on the differences in their application, and this work intends to partially eliminate this gap in research.

\section{Setting objectives}

The purpose of the study is to compare the effectiveness of MM in the traditional and mobile learning environments. An experiment aimed at identifying whether a mobile learning platform increases the effectiveness of learning based on traditional offline activities that involve MM was conducted. The following research objectives have been set:

- introduction of MM in the educational process;

- evaluation of the effectiveness of MM in the traditional offline and mobile learning environments;

- collection and processing of data;

- analysis of the research results to conclude whether a mobile platform increases the effectiveness of learning based on traditional offline activities that involve MM.

\section{METHOD}

\section{Research Design and Sample}

The research is based on the experiment that involved testing of participants; the data obtained were used to compare the results of the groups where MM was used in the traditional offline and mobile learning environments. The experiment was carried out to introduce the MM methods into the educational process. MM was used in the 
entrepreneurship course on launching startups to brainstorm and present a business idea. Medical startups were focused on opening a private medical practice offline, improving medical equipment, or creating an online medical service.

The study was conducted in 2020 and involved 271 undergraduate medical students studying at Sofia University (SU), Bulgaria and Sechenov First Moscow State Medicinal University (FMSMU), Russia. The two universities have an extensive history of cooperation and joint projects. The experiment was aimed at introducing MM into the educational process, as well as conducting practical classes in the offline and online format. The research sample is presented in Table 1.

Table 1

Research sample

\begin{tabular}{lllll}
\hline & SU & FMSMU & Average & Total \\
\hline Number of respondents & 123 & 148 & 136 & 271 \\
\hline Average age & 21.4 & 22.2 & 21.8 & - \\
\hline Number of male respondents & 48 & 63 & 56 & 111 \\
\hline Number of female respondents & 75 & 85 & 80 & 160 \\
\hline Male, $\%$ & $39 \%$ & $43 \%$ & - & $41 \%$ \\
\hline Female, $\%$ & $61 \%$ & $57 \%$ & - & $59 \%$ \\
\hline
\end{tabular}

\section{Experiment and Survey}

There were two student groups; one group of students used MM in the traditional offline learning environment while another relied on a collaborative mobile platform to create mind maps. There were teams of 2-3 students in each group. In turn, each team was assigned a theme in order to develop and present a business idea for a startup. MM was used to brainstorm ideas within a team, as well as to record, present and discuss the results.

\section{Data Analysis}

To evaluate the effectiveness of MM, the complexity of the final student diagram was assessed. Initial data were extracted from the diagrams presented by each student team developing a startup idea. Each team of 2 or 3 students created their final diagram.

Typically, an MM diagram is acyclic; that is, the number of nodes or entities of the diagram is equal to the number of edges or links. However, the students were allowed to use different branches of the entity-relationship diagram. Thus, the complexity of the diagram was characterized by the number of entities, as well as the number of additional horizontal links between the entities of different branches. This metric was taken into account in the experiment. The information was used to assess the complexity of the diagrams developed by students and subsequently compare the effectiveness of MM in the traditional offline and mobile learning environments. Data processing was carried out in Microsoft Excel.

\section{Statistical Processing}

The key research variables were the complexity metrics of the MM diagrams (the number of entities, the number of additional links, and the sum of these two variables). 
These data were analyzed in the two groups that relied on offline and mobile MM. Average, minimum and maximum values were determined for each of the three complexity metrics. The data were analyzed both separately and combined. Then, the complexity of the diagrams presented by the two groups of students was compared.

The study involved second-year undergraduate medical students studying entrepreneurship at both universities under consideration. From this perspective, the students can be considered as a general population of 271 people; $100 \%$ of these subjects took part in the experiment.

\section{Research Limitations}

The study is focused on the educational project aimed at the development of entrepreneurial skills. The results obtained could be affected by the personal qualities of students and the relationships established within the teams, as well as by the personal characteristics of teachers and their professional skills. However, the reliability of the empirical data obtained can be confirmed by the fact that the teachers involved in the study were highly-qualified and motivated. Similar data were obtained for students from two different countries. Thus, the results obtained can be used to improve the effectiveness of MM in the traditional offline and mobile learning environments.

\section{Ethical Issues}

The indicators did not affect the privacy of participants; however, they indirectly characterized their personal abilities. In addition, when analyzing diagrams containing quantitative data, the anonymity of the respondents could not be ensured as the teacher collecting the data knew who the diagram was created by. However, the anonymity was ensured when determining the average indicators and summarizing the research results as personalized data were excluded.

The students were informed about the purpose of the research and the publication of its results. There was no covert observation in the experiment. Persons not participating in the project did not have access to the data processed. Thus, the rights and interests of the research participants were respected.

\section{FINDINGS}

The results of the experiment are described in Table 2. In Table 2, the statistical indicators are described as follows:

M1 is the number of entities on the mind map;

M2 is the number of additional horizontal links on the mind map;

$\mathrm{M} 3=\mathrm{M} 1+\mathrm{M} 2$ is the total metric of the mind map complexity;

Min is the minimum value;

Max is the maximum value;

Avg. is the average value;

$\Delta 1,2$ is the absolute difference between group 1 and group 2 indicators;

$\% 1,2$ is the relative difference between group 1 and group 2 indicators; 
The data were arranged by groups (participating in offline and online learning) and by universities. There are also generalized data on each university that describe the minimum, maximum and average values calculated for the entire research sample (and not as arithmetic means). Absolute $(\square)$ and relative (\%) values were determined to identify the difference between the results of group 1 and group 2 .

Table 2

Experiment results

\begin{tabular}{|c|c|c|c|c|c|}
\hline & & Statistical value & M1 & M2 & M3 \\
\hline \multirow[t]{12}{*}{ SU } & \multirow{3}{*}{$\begin{array}{l}\text { Group } 1 \\
\text { offline }\end{array}$} & Min & 21 & 3 & 24 \\
\hline & & Max & 47 & 10 & 57 \\
\hline & & Avg. & 31.2 & 5.9 & 37.1 \\
\hline & \multirow{3}{*}{$\begin{array}{l}\text { Group } 2 \\
\text { online }\end{array}$} & Min & 19 & 2 & 21 \\
\hline & & Max & 44 & 8 & 52 \\
\hline & & Avg. & 29.6 & 4.8 & 34.4 \\
\hline & \multirow[t]{3}{*}{$\Delta 1.2$} & Min & 2 & 1 & 3 \\
\hline & & Max & 3 & 2 & 5 \\
\hline & & Avg. & 1.6 & 1.1 & 2.7 \\
\hline & \multirow[t]{3}{*}{$\% 1.2$} & Min & $110.5 \%$ & $150.0 \%$ & $114.3 \%$ \\
\hline & & Max & $106.8 \%$ & $125.0 \%$ & $109.6 \%$ \\
\hline & & Avg. & $105.4 \%$ & $122.9 \%$ & $107.8 \%$ \\
\hline \multirow[t]{12}{*}{ FMSMU } & \multirow{3}{*}{$\begin{array}{l}\text { Group } 1 \\
\text { offline }\end{array}$} & Min & 23 & 3 & 26 \\
\hline & & Max & 46 & 9 & 55 \\
\hline & & Avg. & 34.2 & 4.9 & 39.1 \\
\hline & \multirow{3}{*}{$\begin{array}{l}\text { Group } 2 \\
\text { online }\end{array}$} & Min & 18 & 2 & 20 \\
\hline & & Max & 42 & 7 & 49 \\
\hline & & Avg. & 30.1 & 4.1 & 34.2 \\
\hline & \multirow[t]{3}{*}{$\Delta 1.2$} & Min & 5 & 1 & 6 \\
\hline & & Max & 4 & 2 & 6 \\
\hline & & Avg. & 4.1 & 0.8 & 4.9 \\
\hline & \multirow[t]{3}{*}{$\% 1.2$} & Min & $127.8 \%$ & $150.0 \%$ & $130.0 \%$ \\
\hline & & Max & $109.5 \%$ & $128.6 \%$ & $112.2 \%$ \\
\hline & & Avg. & $113.6 \%$ & $119.5 \%$ & $114.3 \%$ \\
\hline \multirow{12}{*}{$\begin{array}{l}\text { Generalized } \\
\text { values }\end{array}$} & \multirow{3}{*}{$\begin{array}{l}\text { Group } 1 \\
\text { offline }\end{array}$} & Min & 21 & 3 & 24 \\
\hline & & Max & 47 & 10 & 57 \\
\hline & & Avg. & 32.8 & 5.4 & 38.2 \\
\hline & \multirow{3}{*}{$\begin{array}{l}\text { Group } 2 \\
\text { online }\end{array}$} & Min & 18 & 2 & 20 \\
\hline & & Max & 44 & 8 & 52 \\
\hline & & Avg. & 29.9 & 4.4 & 34.3 \\
\hline & \multirow[t]{3}{*}{$\Delta 1.2$} & Min & 3 & 1 & 4 \\
\hline & & Max & 3 & 2 & 5 \\
\hline & & Avg. & 2.9 & 1.0 & 3.9 \\
\hline & \multirow[t]{3}{*}{$\% 1.2$} & Min & $116.7 \%$ & $150.0 \%$ & $120.0 \%$ \\
\hline & & Max & $106.8 \%$ & $125.0 \%$ & $109.6 \%$ \\
\hline & & Avg. & $109.9 \%$ & $121.2 \%$ & $111.4 \%$ \\
\hline
\end{tabular}


At Sofia University, there were 20 teams of three participants in group 1 and 21 teams of three participants in group 2. At FMSMU, there were 24 teams of three participants and one team of two participants in group 1. Group 2 had the same structure as group 1. Each team presented their final MM diagram as the result of their work. Thus, 41 diagrams were analyzed in SU and 50 diagrams in FMSMU. In total, $91 \mathrm{MM}$ diagrams were analyzed within the framework of the experiment.

To create diagrams describing the business idea of a startup, it was recommended to use the following basic branches: problems of potential customers, business description, financial indicators (investment structure, capital investments, operating expenses, profit), business model, marketing strategy, as well as any other indicators at the discretion of students. An example of the basic mind map structure is shown in Figure 1. The diagram complexity is described as follows: $\mathrm{M} 1=15 ; \mathrm{M} 2=0 ; \mathrm{M} 3=15$.

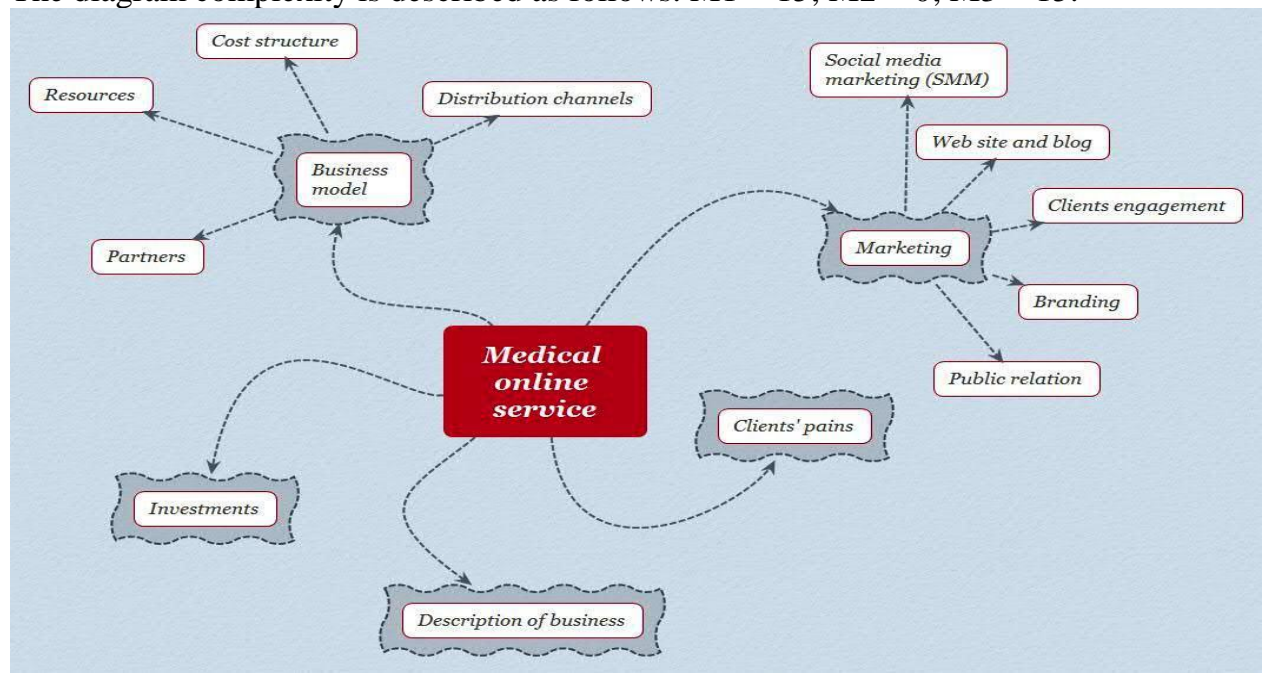

Figure 1

Basic mind map structure to describe the business idea of a startup project

Note: the authors' development

In the offline learning environment, the students were allowed to use any tools. Practical classes were conducted in classrooms and guided by a teacher. For example, a draft diagram might be created during discussions while another more elaborated version was used to present the final results. The diagram could also be modified when completing the assignment. The students were allowed to draw diagrams by hand or use software (the desktop version of XMind was recommended). To present the results, it was also allowed to take a digital photo of a hard copy of the diagram.

The online group relied on mobile channels for communication and collaboration. The students used messengers, online forums, as well as an application to create mind maps (free online service Mindomo was recommended). The students had to create an electronic diagram based on the Mindomo service. The students were also encouraged to maintain online communication within their teams. At the same time, "face-to-face" 
meetings were not prohibited; however, when discussing the results, it was found that students did not use this type of communication.

The effectiveness of the educational process was assessed by the complexity of the final MM diagrams; thus, a more complex diagram was believed to reflect deeper student insights into the essence of the problem under study. Studies in various fields of education have verified the effectiveness of this method. The use of mind mapping has a noticeable effect on increasing students' readiness for future activities and perception of information (Liu \& Yuizono, 2020) and at the level of motivation and academic success (Tan, 2019). It also confirms the assumption that an increase in learning efficiency may be associated with an increase in the complexity of the diagrams used in the learning process (Fadillah et al., 2017; Tan, 2019; Spanoudis \& Demetriou, 2020).

The results of the experiment showed that students who studied in the traditional offline environment performed better compared to those who used their mobile devices. This trend applies to the minimum, maximum, and average values of the three complexity metrics. There is a slight difference in the numerical values of the complexity metrics of the two universities. This is due to the fact that classes at both universities were conducted simultaneously within the framework of the same project based on the same methodology.

At SU, average M3 (the sum of the number of entities and additional horizontal links of the diagram) in group 1 and group 2 was 37.1 and 34.4, respectively. The relative difference between these values is $7.8 \%$. At FMSMU, average M3 was $14.3 \%$ higher in group 1 than in group 2 (39.1 and 34.2, respectively). On the whole, the generalized result (average M3) is $11.4 \%$ higher in group 1 that studied in the traditional offline learning environment than in group 2 that relied on online tools.

\section{DISCUSSION}

The study aimed to identify whether a mobile learning platform increases the effectiveness of learning based on traditional offline activities that involve MM. The results of the study showed that the effectiveness of mobile learning is lower than that of learning based on traditional offline methods. The key disadvantages of mobile learning from the perspective of MM have been identified. It has been observed that the problem is the lack of user-friendliness of mobile devices for the development and analysis of MM.

At the same time, there are a number of studies confirming successful application of MM in medicine and medical education. For example, in the Netherlands, CM and MM were used to develop regional health strategies and policies, as well as to generate reports. $\mathrm{CM}$ and $\mathrm{MM}$ were used to promote healthy lifestyle, provide medical treatment in case of natural disasters, etc. (Katagall et al., 2015). In health care, MM helps to combine theory and practice, record research results, trace links between different areas of knowledge, create knowledge bases, and develop a basis for justifying practical measures (Amin and Hina, 2018).

The analysis of the development of diagnostic skills in medical students based on AM and CM was carried out at South Korea universities; the study involved 95 people (Si et 
al., 2019). When students took tests to diagnose patients, CM was used to present the results. Thus, the visualization and structuring of the results supported the concept of problem-based learning, as well as the argumentation of the proposed solution and the quality of its written presentation.

MM was applied at Canadian universities to train emergency physicians (Gossack-Keenan et al., 2020). Mind maps for diagnosing a situation were alternately modified by nine experienced doctors and nine students that worked in pairs in order to determine the difference in the interpretation of the clinical diagnosis by both groups of respondents. The teaching methods were improved based on the generated diagrams, which were supplemented with important details. In British Columbia, Canada, preventive medicine practitioners also used CM and MM to study the behavior of older people in order to suggest them walking routes and physical activity programs based on their preferences and style of interaction with the society and the environment (Hanson et al., 2013).

In China, MM was used to improve the effectiveness of the postoperative patient care course (Zhang and Yan, 2016). The sample consisted of 60 students. The experimental group used MM for 4 weeks while the control group was trained in accordance with the traditional methodology. The knowledge test showed that learning based on mind mapping improved the performance of students in the written exam, as well as their practical skills to test clinical situations. Thus, learning based on MM can enhance the knowledge and skills of medical students in disease prevention, patient follow-up, and emergency care.

MM contributes to the development of professional self-awareness in medical students. In the study that involved 262 students from Polish universities, the respondents were asked to create mind maps to visualize their ideas of the values and challenges of the work in health care (Janczukowicz and Rees, 2017). At the same time, the analysis of the obtained diagrams made it possible to more clearly reveal student expectations. Further research can help to examine some non-obvious motives in choosing a career path. This referred to demonstrating and understanding the difference between academic professionalism based on personalized knowledge and medical professionalism that is determined by knowledge, ethics and the patient-doctor relationship. The implementation of the concept through visual communication and MM contributes to the development of professional self-awareness in students (Komarova et al., 2019). MM may be more effective for conducting this kind of sociological research than traditional interviews and questionnaires (Tsvetkova, 2018).

\section{CONCLUSIONS}

The results of the experiment showed that students who studied in the traditional offline environment performed better compared to those who used their mobile devices. It has been observed that the problem is the lack of user-friendliness of mobile devices for the development and analysis of MM.

The experiment participants were free to choose any device to perform their assignments. In group 1 that studied in the online learning environment, 50\% of students used their laptops to create diagrams while other students drew mind maps manually. In 
group 2, students were allowed to draw diagrams manually only at the beginning of the experiment. However, the final diagrams had to be submitted electronically. At the same time, $82 \%$ of participants used smartphones and tablets to develop diagrams, and only $18 \%$ used laptops. Thus, the effectiveness of $\mathrm{MM}$ in education depends on the userfriendliness of tools in the mobile environment. There may be certain problems associated with the use of smartphones to perform complex graphic operations. It is necessary to consider the general paradigm of mobile learning as learning regardless of place and time rather than learning limited by the use of smartphones. However, in order to identify more details of the use of smartphones by students when working with mind maps, it is necessary to conduct further research. In order to increase the effectiveness of the use of $\mathrm{MM}$ in the educational process, the following generalized approach can be proposed. At the initial stage, which requires creative activities, it is advisable to draw mind maps manually on paper. Once the diagram is fully completed, it can be digitalized for further storage, use, and improvement. To create electronic diagrams, it is better to use laptops or desktops rather than smartphones. Smartphones can be used to view or send diagrams. However, the analysis of MM diagrams that contain a lot of details can be complicated due to the small smartphone screen size. In the future, it seems necessary to expand the results obtained in this study by objectively assessing the effectiveness of memory cards in achieving academic results and solving complex problems in real practice. The application of this tool in comparison with other methods of memorizing information and deconstructing tasks also needs research.

\section{RECOMMENDATIONS}

The following generalized approach can be proposed: at the initial stage, which requires a creative approach, it is advisable to draw mind maps manually on paper. Once the diagram is fully completed, it can be digitalized for further storage, use, and improvement. To create electronic diagrams, it is better to use laptops or desktops rather than smartphones. Smartphones can be used to view or send diagrams. However, the analysis of MM diagrams that contain a lot of details can be complicated due to the small smartphone screen size.

\section{REFERENCES}

Amin, M., \& Hina, Q. A. (2018). Effect of Mind Mapping Technique on Student Intrinsic Motivation at Higher Education Level. Journal of Research and Reflections in Education, 12(2), 296-313.

Araujo, R. C., \& Gadanidis, G. (2020). Online collaborative mind mapping in a mathematics teacher education program: a study on student interaction and knowledge construction. ZDM Mathematics Education, 52, 943-958.

Beaty, R. E., Seli, P., \& Schacter, D. L. (2019). Network neuroscience of creative cognition: mapping cognitive mechanisms and individual differences in the creative brain. Current opinion in behavioral sciences, 27, 22-30.

Bendixen, L. D., \& Klimow, N. (2019). Participatory Concept Mapping as an Integration Tool in Mixed Methods Research: Exploring Preservice Teachers' Epistemic Cognition and Teaching Orientation. International Journal of Educational Methodology, 5(2), 247-264. 
Bosman, L., \& Fernhaber, S. (2019). Applying authentic learning through cultivation of the entrepreneurial mindset in the engineering classroom. Education Sciences, 9(1), 7.

Boyarchuk, A., Kharchenko, V., \& Sklyar, V. (2018). Models and cases for sustainable university-industry cooperation in IT sector. In Proceedings of the IEEE 9th International Conference on Dependable Systems, Services and Technologies (DESSERT'2018), Leeds, UK (pp. 667-671).

Buzan, T., \& Griffiths, C. (2013). Mind Maps for Business 2nd edn: Using the ultimate thinking tool to revolutionise how you work. Pearson UK.

Camina, E., \& Güell, F. (2017). The neuroanatomical, neurophysiological and psychological basis of memory: Current models and their origins. Frontiers in pharmacology, 8, 438.

Chang, J. H., Chiu, P. S., \& Huang, Y. M. (2018). A sharing mind map-oriented approach to enhance collaborative mobile learning with digital archiving systems. International Review of Research in Open and Distributed Learning, 19(1), 1-25.

Cress, U., Rosé, C. P., Law, N., \& Ludvigsen, S. (2019). Investigating the complexity of computer-supported collaborative learning in action. International Journal of Computer-Supported Collaborative Learning, 14(2), 137-142.

Davies, M. (2011). Concept mapping, mind mapping and argument mapping: what are the differences and do they matter? Higher education, 62(3), 279-301.

Elmunsyah, H., Hidayat, W. N., \& Asfani, K. (2019). Interactive learning media innovation: utilization of augmented reality and pop-up book to improve user's learning autonomy. Journal of Physics: Conference Series, 1193(1), 12-31.

Fadillah, A., Dewi, N. P. L. C., Ridho, D., Majid, A. N., \& Prastiwi, M. N. B. (2017). The effect of application of contextual teaching and learning (CTL) model-based on lesson study with mind mapping media to assess student learning outcomes on chemistry on colloid systems. In International Journal of Science and Applied Science: Conference Series, 1(2), 101-108.

Fauzi, Z. A., \& Degeng, I. N. S. (2018). Implementation of Mind Mapping Learning Model to Improve Learning Outcomes of Civil Education Subject. Journal of K6, Education and Management, 1(3), 9-14.

Gargouri, C., \& Naatus, M. K. (2017). An Experiment in Mind-Mapping and ArgumentMapping: Tools for Assessing Outcomes in the Business Curriculum. e-Journal of Business Education and Scholarship of Teaching, 11, 39-78.

Gossack-Keenan, K., De Wit, K., Gardiner, E., Turcotte, M., \& Chan, T. M. (2020). Showing your thinking: using mind maps to understand the gaps between experienced emergency physicians and their students. AEM Education and Training, 4(1), 54-63.

Han, F., \& Ellis, R. A. (2019). Identifying consistent patterns of quality learning discussions in blended learning. The Internet and Higher Education, 40, 12-19.

Hanson, H. M., Schiller, C., Winters, M., Sims-Gould, J., Clarke, P., Curran, E., \& Ashe, M. C. (2013). Concept mapping applied to the intersection between older adults' 
outdoor walking and the built and social environments. Preventive medicine, 57(6), 785791.

Harris, U. S. (2017). Virtual partnerships: engaging students in e-service learning using computer-mediated communication. Asia Pacific Media Educator, 27(1), 103-117.

Herweg, N. A., \& Kahana, M. J. (2018). Spatial representations in the human brain. Frontiers in human neuroscience, 12, 297.

Hidajat, H. G., Hanurawan, F., Chusniyah, T., \& Rahmawati, H. (2020). Why I'm Bored in Learning? Exploration of Students' Academic Motivation. International Journal of Instruction, 13(3), 119-136.

Janczukowicz, J., \& Rees, C. E. (2017). Preclinical medical students' understandings of academic and medical professionalism: visual analysis of mind maps. BMJ Open, 7(8), e015897.

Kamli, H. M. (2019). The Effect of Using Mind Maps to Enhance EFL Learners' Writing Achievement and Students' Attitudes Towards Writing at Taif University. Arab World English Journal, 232, 1-92.

Katagall, R., Dadde, R., Goudar, R., \& Rao, S. (2015). Concept Mapping in Education and Semantic Knowledge Representation: An Illustrative Survey. Procedia Computer Science, 48, 638-643.

Khalifa, N. A. (2017). Use of Mind Mapping (MM) as an Unconventional Powerful Study Technique in Medical Education. In Managing Knowledge and Innovation for Business Sustainability in Africa (pp. 119-133). Palgrave Macmillan, Cham.

Kirschner, P. A., Buckingham-Shum, S. J., \& Carr, C. S. (2012). Visualizing argumentation: Software tools for collaborative and educational sense-making. Springer Science \& Business Media.

Komarova, A., Tsvetkova, L., Kozlovskaya, S., \& Pronkin, N. (2019). Organisational educational systems and intelligence business systems in entrepreneurship education. Journal of Entrepreneurship Education, 22(5), 1-15.

Kurilova, A., Lysenko, E., Pronkin, N., Mukhin, K., \& Syromyatnikov, D. (2019). The impact of strategic outsourcing on the interaction market in entrepreneurship education. Journal of Entrepreneurship Education, 22(4), 1-11.

Lavoué, É., Monterrat, B., Desmarais, M., \& George, S. (2019). Adaptive Gamification for Learning Environments. IEEE Transactions on Learning Technologies, 12(1), 16-28.

Lin, C.-Y., Huang, C.-K., \& Ko C.-J. (2020). The impact of perceived enjoyment on team effectiveness and individual learning in a blended learning business course: The mediating effect of knowledge sharing. Australasian Journal of Educational Technology, 36(1), 126-141.

Liu, T., \& Yuizono, T. (2020). Mind Mapping Training's Effects on Reading Ability: Detection Based on Eye Tracking Sensors. Sensors, 20(16), 4422.

Marashi, H., \& Kangani, M. (2018). Using Concept Mapping and Mind Mapping in Descriptive and Narrative Writing Classes. Journal of Language and Translation, 8, 93-106. 
Muhlisin, A. (2019). Reading, mind mapping, and sharing (rms): innovation of new learning model on science lecture to improve understanding concepts. Journal for the Education of Gifted Young Scientists, 7(2), 323-340.

Nesbit, J., Niu, H., \& Liu, Q. (2019). Cognitive tools for scaffolding argumentation. In Contemporary Technologies in Education (pp. 97-117). Palgrave Macmillan, Cham.

Nurdin, F. S., \& Damayanti, I. R. (2020). The Role of Critical Thinking as a Mediator Variable in the Effect of Internal Locus of Control on Moral Disengagement. International Journal of Instruction, 13(1), 17-34.

Odah, E.A., \& Hendy, A. M. (2019). Mind Mapping as a Procedural Concept in Design Learning. International Journal of Innovation and Applied Studies, 26, 84-89.

Parikh, N. D. (2016). Effectiveness of teaching through mind mapping technique. The International Journal of Indian Psychology, 3(3), 148-156.

Rapanta, C., \& Walton, D. (2016). The use of argument maps as an assessment tool in higher education. International Journal of Educational Research, 79, 211-221.

Rezapour-Nasrabad, R. (2019). Mind Map Learning Technique: An Educational Interactive Approach. International Journal of Pharmaceutical Research, 11(11593), 1-5.

Si, J., Kong, H. H., \& Lee, S. H. (2019). Developing clinical reasoning skills through argumentation with the concept map method in medical problem-based learning. Interdisciplinary Journal of Problem-Based Learning, 13(1), 5.

Spanoudis, G., \& Demetriou, A. (2020). Mapping Mind-Brain Development: Towards a Comprehensive Theory. Journal of Intelligence, 8(2), 19.

Starov O., Sklyar V., Kharchenko V., Boyarchuk A., \& Phillips C. (2014). A student-inthe-middle approach for successful university and business cooperation in IT. In Proceedings of the University-Industry Interaction Conference (UIIN'2014), Barcelona, Spain (pp. 193-207).

Syakur, A., Musyarofah, L., Sulistiyaningsih, S., \& Wike, W. (2020). The Effect of Project Based Learning (PjBL) Continuing Learning Innovation on Learning Outcomes of English in Higher Education. Budapest International Research and Critics in Linguistics and Education Journal, 3(1), 625-630.

Tan, Z. (2019). Research on the Application of Mind Mapping Concept on Mathematics Education.

Tsvetkova, M. (2018). Lies of the reader: Disadvantages of the sociological research methods for the study of the reading. European Journal of Contemporary Education, 7(1), 190-213.

Zhang, Q. F., \& Yan, L. (2016). Application of mind map in the clinical teaching of postoperative complications of pancreatic cancer patients among undergraduate nursing students. Chinese Journal of Nursing Education, 8, 16.

Zipp, G. P., \& Deluca, D. (2020). Mind Mapping to Enhance Critical Thinking Skills in Physician Assistant Education: A Randomized Controlled Study. Journal of Allied Health, 49(2), 135-140. 